\title{
Pengaruh Lama Penyangraian Terhadap Karakteristik Dan Mutu Organoleptik Seduhan Bubuk Kopi Liberika Tungkal Komposit
}

\author{
${ }^{1}$ Ridawati Marpaung dan ${ }^{2}$ Lutvia \\ ${ }^{1}$ Program Studi Agroteknologi Fakultas Pertanian Universitas Batanghari \\ ${ }^{2}$ Alumni Program Studi Agroteknologi Fakultas Pertanian Universitas Batanghari \\ J1. Slamet Riyadi, Broni Jambi,36122. Telp.+620741-60603 \\ 1e-mail korespondensi : marpaungridawati@yahoo.com
}

\begin{abstract}
The aim of this research was to know the influence of difference roasting duration toward to an organoleptic characteristic and its quality of steepings of coffee powder Liberika Tungkal Komposit.The research had done in Jambi, where fermentation, pulping, drying and hulling procces were done in Mekar Jaya Village, Betara, West Tanjung Jabung Regency. While the coffe been roasting and organoleptic analysis of coffee steeping was conducted in Batanghari University laboratory Jambi. The environmental design was Completely Randomized Design. The treatment designs were roasting duration $: L 1=5$ minutes ; L2 = 10 minutes ; L3 $=15$ minutes and L4 $=20$ minutes. The were three time repeatation in this treatment.The result of this research showed that the roasting duration was significantly effected to the water content, acidity $(\mathrm{pH})$, color, smeel, taste, bitterness and preference of coffee powder liquid. The statistical analysis showed that the 15 minutes duration of roasting had given the highest preference.
\end{abstract}

Keywords : roasting duration, organoleptic quality, coffee Liberika.

\begin{abstract}
Abstrak. Penelitian ini bertujuan untuk mengetahui pengaruh lama penyangraian terhadap karateristik dan mutu organoleptik seduhan bubuk kopi liberika tungkal komposit.Penelitian dilaksanakan di Jambi, dimana proses fermentasi, pulping, pengeringan dan hulling dilakukan di Desa Mekar Jaya, Betara Tanjung Jabung Barat. Sedangkan penyangraian biji kopi serta analisis organoleptik seduhan kopi dilaksanakan di Laboratorium Dasar Universitas Batanghari Jambi. Rancangan lingkungan yang digunakan pada penelitian ini adalah rancangan acak lengkap (RAL). Rancangan perlakuan yaitu lama penyangraian dengan 5 taraf perlakuan sebagai berikut : $1_{1}: 5$ Menit ; $1_{2}: 10$ Menit ; $1_{3}: 15$ Menit dan $1_{4}: 20$ Menit. Setiap perlakuan dilakukan dengan 3 (tiga) ulangan. Dari hasil penelitian diperoleh bahwa lama penyangraian biji kopi liberika berpengaruh nyata terhadap kadar air pH (bubuk kopi), aroma, cita rasa, kepahitan dan kesukaan (seduhan bubuk kopi). Dari hasil penelitian dan analisis statistika panelis memberi penilaian kesukaan tertinggi pada seduhan bubuk kopi dengan lama penyangraian 15 menit.
\end{abstract}

Kata kunci : Lama penyangraian, Mutu organoleptik, Kopi Liberika.

\section{PENDAHULUAN}

Kopi merupakan salah satu komoditas penting yang diperdagangkan secara luas di dunia. Kopi juga menjadi komoditas andalan ekspor dan sumber pendapatan devisa Negara, dengan nilai ekspor mencapai 1.187,2 USD (Badan Pusat Statistik,2017). Selain sebagai sumber pendapatan devisa negara, kopi juga menjadi mata pencaharian bagi petani. Satu hal yang penting diketahui bahwa produksi kopi Indonesia saat ini menduduki peringkat ke empat terbesar di dunia setelah Brazil, Vietnam, dan Kolombia (Pusat Penelitian Kopi dan Kakao Indonesia, 2018).

Menurut data Statistik Kopi Indonesia Tahun 2017, luas areal perkebunan kopi di Indonesia 1.251.703 Ha, dengan produksi mencapai 666.992 ton. Provinsi Jambi merupakan daerah yang banyak melakukan budidaya tanaman kopi. Tahun 2017 luas areal jenis kopi robusta yaitu $25.125 \mathrm{Ha}$, dengan produksi 14.064 ton dan luas areal kopi jenis arabika 1.535 Ha, dengan produksi 241 ton (Badan Pusat Statistik Provinsi Jambi, 2018). Sedangkan kopi jenis liberika banyak di budidayakan di Tanjung Jabung Barat. Tahun 2017 luas areal tanam mencapai 2.610 Ha, dengan produksi 1.081 ton (Badan Pusat Statistik Tanjung Jabung Barat, 2018).

Di Provinsi Jambi, kopi jenis liberika terkonsetrasi di wilayah Kuala Tungkal, Kabupaten Tanjung Jabung Barat. Di Kuala Tungkal berhasil mendapatkan varian baru dari kopi ini yang diberi nama kopi Liberika Tungkal Komposit (Libtukom) (Dinas Perkebunan Provinsi Jambi, 2017).

Salah satu faktor yang mempengaruhi kualitas kopi adalah penanganan pasca panen, diantara nya penentuan masa panen dan proses fermentasi. Mutu organoleptik seperti cita rasa, aroma termasuk dalam sifat-sifat organoleptik yang dapat diukur dengan indra manusia yang dapat dipengaruhi oleh sifat fisik, kimiawi dan faktorfaktor agronomi dan teknologi (Leroy, 2006).

Mutu bubuk kopi pertama kali ditentukan oleh tingkat kemasakan ketika dipanen.Bilamana buah kopi dipanen dalam keadaan masak fisiologis, pembentukan senyawa-senyawa kimia sudah sempurna. Selanjutnya mutu bubuk kopi ditentukan oleh proses fermentasi, dimana proses fermentasi memegang peranan penting dalam pembentukan warna, cita rasa dan aroma yang nantinya akan dimuculkan ketika proses penyangraian. Dari hasil penelitian Marpaung dan Kocu Arianto (2018), bahwa lama fermentasi dengan metode fermentasi kering yang terbaik untuk menghasilkan mutu organoleptik rasa, aroma, kepahitan yang baik adalah 6 hari. Jika fermentasi yang 
dilakukan kurang atau tidak sempurna maka cita rasa khas kopi tidak terbentuk bahkan sering kali dihasilkan cita rasa yang tidak di kehendaki seperti rasa masam, pahit, kelat, dan sangit.

Kualitas bubuk kopi ditentukan oleh proses penyangraian. Menurut Nugroho, Julianty Lumbanbatu, Sri Rahayoe (2009), penyangraian (roasting) merupakan kunci dari tahapan produksi kopi bubuk. Pada proses tersebut terjadi pembentukan aroma dan cita rasa khas kopi yang muncul karena perlakuan panas. Proses penyangraian merupakan seni dan memerlukan keterampilan dan pengalaman untuk mendapatkan kualitas bubuk kopi sesuai dengan permintaan konsumen. Proses penyangraian dilakukan dengan menggunakan suhu yang tinggi. Untuk mendapatkan bubuk kopi, biji kopi disangrai dengan menggunakan suhu $180-240^{\circ} \mathrm{C}$, dimana proses penyangraian membutuhkan waktu 15 sampai 20 menit. Untuk mendapatkan bubuk kopi yang baik, maka dalam proses penyangraian dilakukan pengadukan biji kopi agar uap air cepat terbawa keluar dan panas tedistribusi secara seragam secara keseluruhan. Apabila proses penyangraian sudah selesai maka biji kopi sangrai harus segera dikeluarkan dari mesin penyangrai dan sesegera mungkin didinginkan secara cepat. Apabila proses penyangraian dilakukan terlalu lama akan menyebabkan overroast, sehingga dalam penyangraian ini perlu pengontrolan suhu daan waktu penyangraian yang terkendali.

Berdasarkan hasil penelitian Ayu, Ida dan Arda (2017), agar karakteristik fisik dan mutu sensori bermutu baik pada kopi arabika maka suhu yang digunakan untuk penyangraian disarankan $235^{\circ} \mathrm{C}$ dengan lama penyangraian 14 menit, dengan berat kopi yang disangrai sebanyak 200 g. Proses penyangraian ditandai dengan adanya penurunan rendemen, kadar air dan adanya perbedaan warna kecerahan pada bubuk kopi. Hal ini disebabkan karena adanya proses karamelisasi gula yang menyebabkan timbulnya warna. Selain itu juga nilai keasaman pada bubuk kopi semakin menurun menuju ke $\mathrm{pH}$ netral dengan semakin lama proses penyangraian.

\section{METODE PENELITIAN}

Penelitian telah dilaksanakan di Jl. H.Ibrahim RT 18 Kecamatan Kota Baru, Kota Jambi untuk pelaksanaan fermentasi, pulping, penggilingan dan hulling.Sedangkan penyangraian biji kopi serta analisis organoleptik seduhan kopi dilaksanakan di Laboratorium Dasar Universitas Batanghari Jambi.

Rancangan lingkungan yang digunakan pada penelitian ini adalah rancangan acak lengkap (RAL). Rancangan perlakuan yaitu lama peyangraian dengan 5 taraf perlakuan sebagai berikut:L1: 5 Menit ; L2: 10 Menit ; L3: 15 Menit ; L4: 20 Menit. Setiap perlakuan dilakukan pengulangan sebanyak 3 kali, sehingga terdapat 12 unit percobaan. Setiap unit percobaan menggunakan biji kopi beras sebanyak 200 gr, sehingga dibutuhkan 2,4 kg biji kopi kering.

\section{Pelaksanaan \\ Pemanenan}

Biji kopi yang sudah matang secara fisologis dengan ciri-ciri buah kopi sudah berwarna merah, dipetik dari pohon kopi, selanjutnya disortasi untuk memisahkan biji kopi dari ranting- ranting yang ikut dan dari biji kopi yang rusak. Buah kopi yang digunakan untukseluruh perlakuan adalah $1 \mathrm{~kg}$.

\section{Pengupasan Kulit Buah Kopi (Pulping)}

Tujuan Pulping untuk memisahkan biji kopi dari kulit luar dan mesocrap (bagian daging). Pengupasan dilakukan menggunakan mesin atau secara manual.

\section{Fermentasi}

Biji kopi yang sudah, dipulping difermentasi dengan cara memasukkan ke dalam polibag ukuran $5 \mathrm{~kg}$, kemudian polibag ditutup dengan daun pisang, Polibag disusun diletakkan diatas papan. lama waktu fermentasi yaitu 6 hari. Setiap 2 hari sekali dilakukan pengadukan agar fermentasi merata.

\section{Pengeringan (draying)}

Pengeringan bertujuan untuk mengurangi kandungan air dalam biji kopi yang semula $60-65 \%$ menjadi sekitar $12 \%$. Pengeringan dilakukan dengan penjemuran.Rata-rata pengeringan antara seminggu sampai 10 hari.

\section{Penyangraian}

Biji kopi yang sudah kering diambil $200 \mathrm{~g}$, kemudian disangrai dengan menggunakan coffee roastingyang telah ditentukan. Suhu penyangraian untuk setiap perlakuan sama yaitu $240 \square \mathrm{C}$ dan waktu penyangraian yang berbeda sesuai dengan perlakuan. 


\section{Penggilingan}

Proses penggilingan biji kopi liberika dilakukan dengan menggunakan alat penggiling kopi. Penggilingan dilakukan hingga menghasilkan bubuk kopi yang halus. Bubuk kopi yang telah dihaluskan selanjutnya diayak dengan menggunakan ayakan 250 mesh sehingga diperoleh bubuk kopi dengan ukuran yang seragam.

\section{Penyeduhan}

Penyeduhan bubuk kopi liberika dengan cara menyeduh bubuk kopi dengan menggunakan air yang mendidih. Penyeduhan bubuk kopi dilakukan dengan menggunakan takaran yang sama yaitu $60 \mathrm{~g}$ bubuk kopi, $40 \mathrm{~g}$ gula dan $400 \mathrm{ml}$ air mendidih.

\section{Pelaksanaan Uji Organoleptik}

Panelis dalam uji organoleptik sebanyak 10 orang, panelis ini adalah orang-orang yang terbiasa minum kopi. Agar tidak terjadi salah persepsi tentang seduhan bubuk kopi liberika, sebelum dilakukan uji organoleptik panelis akan dikenalkan tentang seduhan bubuk kopi liberika.

Dalam pelaksanaan uji organoleptik suasana dalam keadaan rileks, panelis tidak dalam keadaan kenyang dan lapar.Sebelum pengujian organoleptik, panelis terlebih dahulu berkumur-kumur dengan menggunakan air mineral.Setiap panelis diberikan satu gelas seduhan bubuk kopi liberika, selanjutnya panelis terlebih dahulu menilai warna (tingkat kehitaman), menghirup aroma untuk menilai aroma dan selanjutnya mencicip untuk menentukan cita rasa, kepahitan dan kesukaan.Setelah mencicipi seduhan bubuk kopi liberika sampel pertama panelis diminta untuk berkumur-kumur agar sisa dari kopi yang sebelumnya hilang.Panelis diberikan jeda waktu 5 menit, kemudian baru mencicipi bubuk kopi sampel berikutnya.Penilaian organoleptik dilakukan oleh panelis dengan panduan kuisioner yang telah disediakan.

\section{Peubah Yang Diamati}

a. Warna Seduhan Bubuk Kopi

Warna yang diamati adalah tingkat kehitaman pada seduhan bubuk kopi yang sudah digiling menjadi bubuk kopi siap seduh. Penilaian tingkat kehitaman bubuk kopi dipadu menggunakan bagan/gradasi warna yang telah ditetapkan, sebagai berikut:
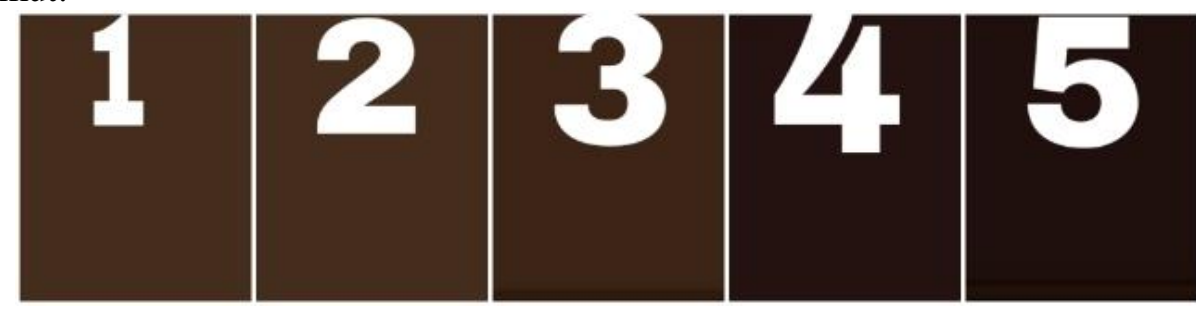

Gambar 1. Skala Warna Bubuk Kopi

\section{b. Aroma Seduhan Bubuk Kopi}

Aroma bubuk kopi yang diamati dengan indra penciuman, yaitu dengan mencium aroma bubuk kopi yang keluar dari hasil seduhan bubuk kopi.

\section{c. Cita rasa}

Pengamatan cita rasa dengan cara mencicipi seduhan bubuk kopi yang sudah disiapkan.

\section{d. Kepahitan}

Pengamatan tingkat kepahitan dengan cara mencicip seduhan bubuk kopi yang telah disiapkan

\section{e. Kesukaan}

Penilaian kesukaan dilakukan dengan menggambungkan seluruh penilaian organoleptik seperti cita rasa, aroma, kepahitan dan warna seduhan bubuk kopi.

Pengujian organoleptik dilakukan oleh penelis sebanyak 10 orang dengan menggunakan panduan format uji skorsing pada lampiran 1 .

\section{f. Kadar Air}

Bubuk kopi yang telah kering diukur kadar airnya dengan cara dioven selama 24 jam pada suhu $80^{\circ} \mathrm{C}$. Pengovenan dilakukan sampai diperoleh kadar air biji kopi yang konstan. Kadar air dihitung dengan rumus sebagai berikut: 
Ridawati Marpaung dan Lutvia. Pengaruh Lama Penyangraian Terhadap Karakteristik Dan Mutu Organoleptik Seduhan

$K A=\frac{\mathrm{M} 2-\mathrm{M} 3}{\mathrm{M} 2-\mathrm{M} 1} \mathrm{X} 100 \%$

Keterangan:

$\mathrm{Ka}=$ Kandar air

$\mathrm{M} 1=$ Berat cawan + tutup kosong

$\mathrm{M} 2=$ Berat cawan + tutup + biji kopi kering yang telah dikeringkan

M3= Berat cawan + tutup + biji kopi kering yang telah dikeringkan

\section{pH Biji Kopi Kering}

Pengukuran $\mathrm{pH}$ bubuk kopi dilakukan dengan menggunakan $\mathrm{pH}$ Meter.10 gram bubuk kopi dilarutkan ke dalam $100 \mathrm{ml}$ air. Elektroda dicelupkan ke dalam larutan, didiamkan 10 menit untuk mendapatkan pembacaan yang stabil. Angka yang terbaca kemudian dicatat sebagai $\mathrm{pH}$ sampel.

\section{Analisis Data}

Untuk melihat pengaruh lama fermentasi yang berbeda dilakukan pengamatan sebagai berikut:

1. Pengamatan parameter warna, aroma, cita rasa kepahitan dan kesukaan dilakukan dengan uji presepsi dengan skala likert 5 skala kemudian di tabulasi data, dilanjutkan dengan analisis uji lanjut DNMRT pada paraf $\alpha$ 5\%

2. Pengujian peubah $\mathrm{pH}$ bubuk kopi kering, dan penentuan kadar air dilakukan tabulasi data kemudian dilanjutkan dengan analisis ragam dan uji lanjut DNMRT pada taraf $\alpha 5 \%$.

\section{Warna seduhan bubuk Kopi}

\section{HASIL DAN PEMBAHASAN}

Dari hasil analisis ragamdan uji lanjut DNMRT pada taraf $\alpha 5 \%$ terhadap skornilai rata-rata warna seduhan bubuk kopi pada waktu penyangraian yang berbeda. dapat dilihat dari Tabel 1.

Tabel 1.Skor nilai rata-rata warna

\begin{tabular}{ccc}
\hline Perlakuan & Skor & Warna Kopi* \\
\hline 5 Menit & $39,3 \mathrm{a}$ & Coklat \\
10 Menit & $56 \mathrm{~b}$ & Coklat Kegitaman \\
20 Menit & $93,3 \mathrm{c}$ & Hitam \\
12 Menit & $94 \mathrm{c}$ & Hitam \\
\hline
\end{tabular}

Keterangan : Angka-angka yang diikuti huruf kecil yang sama berbeda tidak nyata menurut uji DNMRT taraf $\alpha$ 5\% *: Interpretasi skor Skala Likert 5 skala

\section{Aroma seduhan bubuk Kopi}

Dari hasil analisisragam dan uji lanjut DNMRT pada taraf $\alpha$ 5\% terhadap skor nilai rata-rata aroma seduhan bubuk kopi dengan lama penyangraian yang berbeda dapat dilihat pada Tabel 2.

Tabel 2. Skor nilai rata-rata aroma

\begin{tabular}{ccc}
\hline Perlakuan & Skor & Aroma Kopi* \\
\hline 5 Menit & $48,7 \mathrm{a}$ & Agak disukai \\
10 Menit & $58,7 \mathrm{~b}$ & Agak disukai \\
20 Menit & $64,7 \mathrm{bc}$ & Disukai \\
15 Menit & $70,7 \mathrm{c}$ & Disukai \\
\hline
\end{tabular}

\section{Cita Rasa seduhan bubuk Kopi}

Dari hasil analisis ragam dan Hasiluji DNMRT pada taraf $\alpha 5 \%$, terhadap skor nilai rata-rata cita rasa seduhan bubuk kopipenyangraian yang berbeda dapat dilihat pada Tabel 3.

Tabel 3.Skor nilai rata-rata cita rasa

\begin{tabular}{ccc}
\hline Perlakuan & Skor & Cita Rasa Kopi* \\
\hline 5 Menit & $48,7 \mathrm{a}$ & Agak disukai \\
10 Menit & $56 \mathrm{a}$ & Agak disukai \\
20 Menit & $54,7 \mathrm{a}$ & Agak disukai \\
15 Menit & $68,7 \mathrm{~b}$ & Disukai \\
\hline
\end{tabular}


Ridawati Marpaung dan Lutvia. Pengaruh Lama Penyangraian Terhadap Karakteristik Dan Mutu Organoleptik Seduhan Bubuk Kopi Liberika Tungkal Komposit

\section{Kepahitan seduhan bubuk Kopi}

Dari hasi analisis ragam dan uji lanjut DNMRT pada taraf $\alpha 5 \%$ terhadap skor nilai rata-rata kepahitan seduhan bubuk kopi dapat dilihat pada Tabel 4.

Tabel 4.Skor nilai rata-rata kepahitan

\begin{tabular}{ccc}
\hline Perlakuan & Skor & Kepahitan Kopi* \\
\hline 5 Menit & $48,3 \mathrm{a}$ & Agak Pahit \\
10 Menit & $52,7 \mathrm{a}$ & Agak Pahit \\
20 Menit & $77,3 \mathrm{~b}$ & Pahit \\
15 Menit & $82,0 \mathrm{~b}$ & Sangat Pahit \\
\hline
\end{tabular}

\section{Kesukaan seduhan bubuk Kopi}

Dari hasil analisis ragam danuji lanjut DNMRT pada taraf $\alpha 5 \%$ terhadap skor rata-ratanilai kesukaan seduhan bubuk kopi dapat dilihat pada Tabel 5.

Tabel 5.Skor rata-rata nilai kesukaan

\begin{tabular}{ccc}
\hline Perlakuan & Skor & Kesukaan Kopi* \\
\hline 5 Menit & 49,3 & Agak disukai \\
10 Menit & $60 \mathrm{~b}$ & Disukai \\
20 Menit & $62 \mathrm{bc}$ & Disukai \\
15 Menit & $71,3 \mathrm{c}$ & Disukai \\
\hline
\end{tabular}

\section{Kadar Air Bubuk Kopi}

Dari hasil analisis ragam dan uji DNMRT dengan taraf 5\%, kadar air bubuk kopi dapat dilihat pada Tabel 6.

Tabel 6.Nilai rata- ratakadar air bubuk kopi

\begin{tabular}{cc}
\hline Perlakuan & Kadar Air \% \\
\hline 5 Menit & $4,9 \mathrm{a}$ \\
10 Menit & $4,2 \mathrm{a}$ \\
20 Menit & $2,4 \mathrm{~b}$ \\
15 Menit & $2,4 \mathrm{~b}$ \\
\hline
\end{tabular}

\section{pH bubuk Kopi}

Dari hasil analisis ragam dan uji DNMRTdengan taraf uji $\alpha$ 5\%, $\mathrm{pH}$ nilai rata-rata $\mathrm{pH}$ bubuk kopi dapat dilihat pada Tabel 7 .

Tabel 7.Nilai rata-rata $\mathrm{pH}$ bubuk kopi

\begin{tabular}{cc}
\hline Perlakuan & $\mathrm{pH}$ \\
\hline 5 Menit & $4,9 \mathrm{a}$ \\
10 Menit & $5,2 \mathrm{~b}$ \\
20 Menit & $6 \mathrm{c}$ \\
15 Menit & $6,3 \mathrm{~d}$ \\
\hline
\end{tabular}

Keterangan: angka-angka yang di ikuti huruf kecil yang sama berbeda tidak nyata menurut uji DNMRT taraf $=\alpha 5 \%$

Penyangraian adalah proses yang sangat penting untuk mengembangkan sifat organoleptik, baik kesan warna, aroma, cita rasa, kepahitan dan kesukaan pada seduhan bubuk kopi. Kombinasi dari sifat-sifat fisik dan sifat organoleptik pada seduhan bubuk kopi ini akan menentukan tingkat kesukaan pada panelis. Secara persentase, proses roasting memiliki pengaruh 30\% dalam sumbangan aroma dan rasa. Cita rasa dan kepahitan sangat dipengaruhi oleh besarnya suhu dan waktu penyangraian.

Menurut Safitri (2019), bahwa pada penyangraian terjadi proses pirolisis yang menyebabkan terjadinya proses oksidasi, reduksi, hirolisis, polimerisasi, dekarboksilasi dan perubahan kimia lainnya yang membentuk senyawa yang menentukkan aroma dan cita rasa pada seduhan bubuk kopi. Dalam penelitian ini penyangraian dilakukan dengan menggunakan lama penyangraian 5, 10, 15 dan 20 menit pada suhu $240^{\circ} \mathrm{C}$. Dari hasil pengamatan dan penelitian, semakin lama waktu penyangraian maka tingkat kematangan biji kopi semakin mengarah pada tingkat kegosongan, hal ini ditandai dengan terbentuknya warna biji kopi menjadi lebih hitam dan aroma yang dihasilkan semakin tajam. 
Ridawati Marpaung dan Lutvia. Pengaruh Lama Penyangraian Terhadap Karakteristik Dan Mutu Organoleptik Seduhan Bubuk Kopi Liberika Tungkal Komposit

Dari hasil analisis ragam (Tabel1) diperoleh bahwa warna seduhan bubuk kopi yang disangrai dengan 15 dan 20 menit menghasilkan warna seduhan bubuk kopi dengan kriteria hitam sedangkan biji kopi yang disangrai selama 5 dan 10 menit menghasikan warna coklat hingga coklat kehitaman. Perbedaan tingkat warna bubuk kopi dengan lama penyangraian 5, 10, 15 dan 20 menit dapat dilihat pada gambar sebagai berikut :

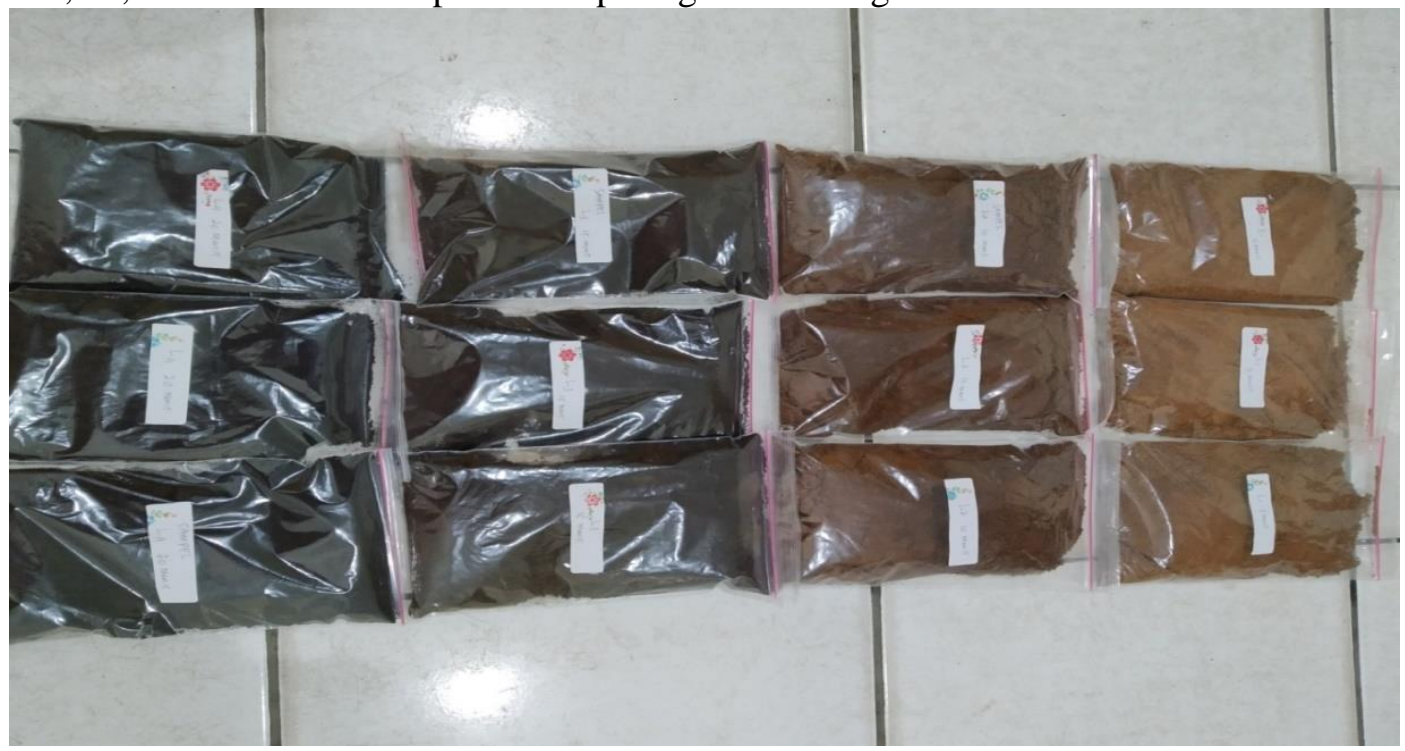

Gambar 2. Tingkat kehitaman bubuk kopi hasil penyangraian dengan waktu 5, 10, 15 dan 20 menit pada suhu $240^{\circ} \mathrm{C}$

Dari Gambar 2 dapat dilihat perbedaan tingkat kehitaman pada bubuk kopi, dimana semakin lama penyangraian biji kopi, tingkat kematangan biji kopi sudah mengarah kegosongan, sehingga warna yang dihasilkan akan semakin hitam. Sedangkan penyangraian dengan waktu 5 dan 10 menit, tingkat kematangan biji kopi belum mengarah kegosongan sehingga warna bubuk kopi yang dihasilkan kategori coklat terang hingga coklat kehitaman.

Pembentukan warna pada biji kopi pertama kali ditentukan oleh proses fermentasi, dimana dalam proses fermentasi terjadi pembentukan calon warna akibat aktivitas mikroorganisme dan reaksi enzimatis. Selanjutnya pembentukan warna ditentukan oleh suhu dan waktu proses penyangraian. Selama penyangraian berlangsung terjadi proses pirolisis (karamelisasi) dalam biji kopi. Secara kimiawi proses ini ditandai dengan hepolusi gas $\mathrm{CO}_{2}$ dalam jumlah banyak dari ruang sangrai. Secara fisik pirolisis ditandai dengan perubahan warna biji kopi dari kehijauan menjadi coklat muda hingga coklat kehitaman.Tahap ini sering disebut tahap pencoklatan (Browning).

Hasil analisis ragam (Tabel 2) menunjukkan bahwa aroma biji kopi yang disangrai selama 15 dan 20 menit disukai oleh panelis sedangkan yang disangrai dengan waktu 5 dan 10 menit agak disukai oleh panelis. Pada penyangraian 20 menit biji kopi sudah mengalami kegosongan sehingga aroma yang dihasilkan mulai mengalami penyimpangan.Penyangraian biji kopi selama 15 menit menghasilkan biji kopi dengan tingkat kematangan yang lebih baik (tidak mentah dan tidak terlalu gosong) sehingga memunculkan aroma yang khas pada bubuk kopi yang disukai konsumen pada umumnya.

Hasil analisis ragam (Tabel 3) menunjukkan bahwa cita rasa seduhan bubuk kopi yang disagrai selama 15 menit lebih disukai oleh panelis,sedangkan cita rasa yang agak disukai adalah dengan lama penyangraian 510 dan 20 menit.Menurut Sari (2001),proses penyangraian mengakibatkan senyawa karbohidrat terdegrarasi menjadi glukosa dan gula-gula sederhana yang menghasilkan rasa manis.Selama penyangraian kandungan kafein, asam klorogenat dan trigonelin memberi kontribusi dalam pembentukan rasa pada seduhan bubuk kopi.

Pengujian organoleptik terhadap kepahitan seduhan bubuk kopi,panelis memberi penilaian bahwa semakin lama penyagraian seduhan bubuk kopi semakin pahit. Dari Tabel 4 menunjukkan bahwa seduhan bubuk kopi yang disangrai selama 5 dan 10 menit menurut panelis agak pahit tetapi disangrai selama 20 menit sangat pahit.Rasa pahit pada seduhan bubuk kopi juga ditentukan oleh alkaloid yaitu kafein yang mengalami sublimasi membentuk kafeol (Sari., L.I., 2001).

Dari Tabel 5 menunjukkan bahwa panelis memberi penilaian kesukaan tertinggi pada seduhan bubuk kopi dengan waktu penyangraian 15 menit. Hal ini terjadi karena penyangraian dalam waktu 15 menit biji kopi roasting sudah cukup kematangannya artinya tidak mentah dan tidak gosong.Kondisi tingkat kematangan roasting pada waktu 15 menit menghasilkan aroma dan cita rasa yang baik warna seduhan bubuk kopi dan tingkat kepahitan sesuai untuk panelis.

Dari hasil analisis ragam (Tabel 6) menunjukan bahwa kadar air bubuk kopi tertinggi diperoleh dari hasil penyangraian pada waktu 5 menit $(4,9 \%)$ dan yang terendah pada bubuk kopi hasil penyangraian pada waktu 15 dan 
20 menit (2,4\%). Semakin lama waktu penyangraian semakin banyak air yang diuapkan dari biji kopi. Hal ini terjadi karena ketika proses penyangraian berlangsung, terjadi perpindahan panas dari media sangrai ke biji kopi yang mengakibatkan terjadinya perubahan massa air dari biji kopi menjadi uap air.

Dari Tabel 7 menunjukkan bahwa semakin lama waktu penyangraian, $\mathrm{pH}$ bubuk kopi mengalami peningkatan.Berdasarkan hasil perhitungan $\mathrm{pH}$ bubuk kopi yang disangrai pada selama 20 menit lebih tinggi $(6,3)$ dan $\mathrm{pH}$ bubuk kopi yang disangrai 5 menit lebih rendah (4,9). Peningkatan $\mathrm{pH}$ bubuk kopi akibat semakin lamanya proses penyangraian disebabkan berbagai jenis senyawa volatil seperti aldehida, furfural, keton, alkohol, ester, asam format dan asam asetat mengalami penguapan (Mulato, 2002) dalam Purnamayanti., N., P., A., dkk @ 0017).

\section{KESIMPULAN}

Lama penyangraian biji kopi liberika berpengaruh nyata terhadap kadar air pH (bubuk kopi), aroma, cita rasa, kepahitan dan kesukaan (seduhan bubuk kopi). Penilaian kesukaan tertinggi pada seduhan bubuk kopi dengan lama penyangraian 15 menit.

\section{DAFTAR PUSTAKA}

Marpaung R dan K Arianto.2018. Karakteristik Fisik Bubuk Kopi Dan Mutu Organoleptik Seduhan Bubuk Kopi Liberia Tungkal Komposit Pada Beberapa Metode Feremntasi.Jurnal Media Pertanian Vol. 3 No. 2 Tahun 2018 Hal. $72-78$

Purnamayanti.,N., P., A., Ida Bagus Putu Gunadya, Gede Arda (2017), Pengaruh suhu dan penyangraian terhadap karakteristik Fisik dan mutu sensori kopi arabika (Coffea arabica. L). Jurnal BETA (BIOSISTEM DAN TEKNIK PERTANIAN). Program studi Teknik Pertanian, Fakultas Teknologi Pertanian Universitas Udayana.

Nugroho, J, Julianty Lumbanbatu, dan Sri Rahayoe, S. 2009. Pengaruh Suhu Dan Lama Penyangraian Tehadap Sifat Fisik-Mekanis Biji Kopi Robusta. Makalah Bidang Teknik Produk Pertanian,ISSN2081-7152Diakses Dari:Https://Repository.Ugm.ac.id/33122/1/A20_Joko_Nugroho.Pdf

Sari, L.I. 2001. Mempelajari Proses Pengolahan Bubuk Kopi (Coffea Canephora) Alternative Dengan Menggunakan Suhu Dan Tekanan Rendah. Skripsi S1. Fakultas Pertanian Institute Pertanian Bogor, Bogor. 